\title{
O fazer docente no processo ensino-aprendizagem: reflexões e desdobramentos na Geografia escolar
}

\author{
The teacher in the teaching-learning process: reflections and \\ unfolding paths for Geography at school
}

\section{Lineu Aparecido PaZ e Silva ${ }^{\mathrm{a}}$}

\author{
${ }^{a}$ Professor de Geografia da Educação Básica pela Secretaria Municipal de Educação \\ Alto Longá/PI, doutor em Geografia pela Universidade de Brasília (UnB). \\ E-mail: lineuprofgeo@hotmail.com
}

\begin{abstract}
Este estudo apresenta reflexões acerca da educação geográfica que, no cenário de transformações da prática em sala de aula, vivencia processos de adaptações. A Geografia, enquanto ciência da sociedade, experimenta uma fase de intensas mudanças não somente nas discussões de seu objeto de estudo, mas na sua forma de ensinamento. A aprendizagem representa a construção contínua de etapas e atividades realizadas por docente e educando, que objetivam a assimilação dos conhecimentos. A prática docente, hoje, precisa questionar os problemas do ambiente escolar, além de lançar um olhar crítico aos fenômenos atuais. O professor de Geografia deve estar preparado, planejar conteúdos e analisar situações de ensino para favorecer a aprendizagem. Verifica-se que a gestão e o planejamento escolar devem estar mais relacionados à realidade docente. O caminho benéfico para a educação geográfica está vinculado ao processo de ensino, ao acompanhamento sistemático do educando, aos objetivos do planejamento e, além disso, a que o ensino ocorra de maneira que proporcione a construção do conhecimento. Ensinar Geografia representa contribuir para a sociedade no tocante à educação e à formação de atitudes e valores dos educandos, atitudes estas que se levam para a vida, podendo contribuir para solucionar problemas que serão enfrentados na sociedade.

Palavras-chave: ensino de Geografia, prática docente, processo ensino-aprendizagem, educação básica.
\end{abstract}

This study discusses Geography education, which, considering drastic changes in teaching practice, is being adapted to a new reality. Such changes not only involve discussion about its object of study, but also its form of teaching. Learning represents the continuous construction of stages and activities carried out by teachers and students in educational institutions. In the case of today's teaching practice, this requires questioning the problems of the school environment, as well as having a critical look at ongoing social phenomena. The Geography teacher needs to be prepared, plan the contents and analyze the situations of teaching in the classroom as to favor learning. Analysis of the present discussions showed that school management and planning needs to be more related to the teaching reality. The beneficial path towards teaching Geography is related to the teaching process, to the systematic follow-up of students, to planning objectives, in a way that teaching can foster the construction of knowledge. Teaching Geography represents a contribution to society in terms of education and formation of attitudes and values of learners as citizens, with such attitudes being carried along the individual's life, also allowing them to resolve social problems to be faced in the future.

Keywords: teaching of Geography, teaching practice, teaching-learning process, basic education. 


\section{INTRODUÇÃO}

Este estudo apresenta reflexões acerca da educação geográfica que, diante do cenário de metamorfoses da prática em sala de aula, vivencia processos de adaptações diante de novas realidades. É preciso ressaltar que cenários inovadores aparecem no ensino de Geografia e, com eles, situações e possibilidades. Tecnologias e interpretações surgem em decorrência disso. As imagens, a fotografia, os jornais, os livros, a televisão, o vídeo, o computador, enfim, todos estes elementos refletem o cenário educacional da atualidade. A prática de ensino dos dias atuais não pode se prender à transmissão de informações, à memorização ou a aplicar conteúdos de maneira mecânica.

Outro destaque a ser mencionado nesta análise diz respeito ao processo ensino-aprendizagem que se define pela sequência de atividades realizadas pelo professor e pelo educando que objetiva assimilar os conhecimentos. $\mathrm{O}$ ensino e a aprendizagem se direcionam de acordo com a visão do professor e de sua maneira de trabalhar os conteúdos em sala de aula e, além disso, com o conhecimento das funções didáticas, da compatibilidade dos conteúdos e das disciplinas com os procedimentos metodológicos.

A aprendizagem do educando não só reflete o trabalho do professor, mas também outros fatores, como a gestão e o planejamento escolar, por exemplo. A gestão escolar caracteriza a maneira como a instituição de ensino está sendo administrada, ou seja, de maneira participativa, democrática ou de maneira que não haja a participação das pessoas envolvidas no contexto da escola. Representa uma forma de garantir o funcionamento da escola e o direcionamento de todas as atividades que a envolvem, principalmente a atividade pedagógica, com desdobramentos no ensino e na aprendizagem.

Nesse sentido, existe relação intrínseca entre a aprendizagem e a prática docente, caracterizando-se como o desafio a ser encarado pelo docente na educação básica em sua prática pedagógica, no sentido de contribuir para a aprendizagem.

A atividade do professor no contexto escolar tem relação com a atividade profissional e práticas pedagógicas atuais, pois, de fato, existe um cenário de ensino inovador para o aluno. Os autores que contribuíram para o embasamento e a elaboração deste estudo foram Vesentini (1987), Cavalcanti (1991), Soja (1993), Callai (2013), Castells (1999), Albuquerque (2013), Libâneo (2004), Castrogiovanni (2000), Coll (1998),
Evangelista (2007), Piaget (1976), Lück (2000), Silva (2009), Turra (2002) e Tardiff (2008).

\section{Ensino de Geografia E EDUCAÇÃo BÁSICA}

A Geografia, enquanto ciência da sociedade, experimenta uma fase de intensas mudanças não somente nas discussões acerca de seu objeto de estudo, mas na sua forma de ensinamento em sala de aula. É a ciência voltada para a análise do espaço geográfico e suas múltiplas relações com o meio natural.

E o ensino de Geografia, diante do cenário de metamorfoses do espaço, passa por processo de adaptação a essas novas transformações que se refletem na prática docente em sala de aula. Na educação geográfica surge a necessidade de se entender o real significado do termo espaço geográfico, ou seja, para que serve e que relação existe com o local de moradia, da sociedade em seu cotidiano. O trabalho de Geografia nas escolas reflete a dinâmica espacial vivenciada pela sociedade.

O ensino dos dias atuais representa um novo momento histórico e social em que existe uma nova relação da sociedade com o conhecimento, e o trabalho do professor representa uma maneira de lidar com situações inovadoras que caracterizam novas aprendizagens. Nesse aspecto, o ensino de Geografia representa uma contribuição importante,

tendo em vista os grandes desafios colocados ao professor de Geografia, no atual momento histórico e social. As mudanças provocadas pelo desenvolvimento técnico-científico-informacional reestruturaram a relação da sociedade com o conhecimento. Essa nova realidade afeta o trabalho de todos os professores(as), mas, em especial, os(as) professores(as) de Geografia, pois estes(as) lidam com um conhecimento que quer dar conta de explicar as variadas configurações do espaço, este entendido como suporte de relações sociais, econômicas e culturais complexas a um só tempo determinantes e determinadas por ele. (SILVA, 2009, p. 9)

O ensino de hoje se volta para a formação de cidadãos que vivem o espaço com problemas e transformações de ordem natural e cultural, e, em virtude disso, o domínio de certos conteúdos em Geografia representa um processo importante. Além disso, existe a necessidade de análise mais aprofundada acerca de conteúdos e metodologias que facilitem a aprendizagem. 
O ensino de Geografia nos últimos anos se caracterizou por representar objeto de constantes debates por importantes teóricos que estudam a educação e o ensino de Geografia. O certo é que, nos dias atuais, este tema deve ser voltado à cognição, ou seja, um ensino que mostre a importância do estudo e as suas múltiplas funções. Nesse sentido, concordando com Vesentini (1987, p. 78),

um ensino crítico de Geografia não consiste pura e simplesmente em reproduzir num outro nível o conteúdo da(s) Geografia(s) crítica(s), acadêmica(s); pelo contrário, o conhecimento acadêmico (ou científico) deve ser reatualizado, reelaborado em função da realidade do aluno e do seu meio [...] não se trata nem de partir do nada e nem simplesmente aplicar no ensino o saber científico, deve haver uma relação dialética entre esse saber e a realidade do aluno - daí o professor não ser um mero reprodutor, mas um criador.

O conteúdo ministrado não se resume a mera reprodução nem é objeto apenas de transmissão, o que de fato deve ocorrer é a assimilação deste junto aos educandos e que o ensino seja objeto de contínua construção.

No cenário educacional, surge a necessidade de haver uma relação entre os conteúdos e a ação pedagógica, e o aluno é o sujeito principal no ensino de Geografia. O cenário do século XXI necessita do ensino que mostre aos alunos as transformações espaciais e, para isso, os conteúdos devem ser constantemente atualizados e revisados para que a aprendizagem possa ocorrer de maneira mais rápida e eficaz, e a estratégia de ensino deve ser favorável à realidade do aluno. Nessa discussão,

o domínio da ciência geográfica, refletindo na matéria de ensino, bem como de seus métodos próprios é, sem dúvida, condição prévia para o seu ensino. Mas cumpre destacar o fato de que nem a ciência é idêntica à matéria de ensino, nem os métodos da ciência idênticos aos métodos de ensino, ainda que guardem entre si uma unidade. Quando se trata em ensinar as bases da ciência, opera-se uma transmutação pedagógico-didática, em que os conteúdos da ciência se transformam em conteúdos de ensino. Há, pois uma autônima relativa dos objetivos sociopedagógicos e dos métodos de ensino, pelo que a matéria de ensino deve organizar se de modo que seja didaticamente assimilável pelos alunos, conformidade, nível de desenvolvimento mental, condições prévias de aprendizagem e condições socioculturais. (CAVALCANTI, 1991, p. 35)
É notório que situações inovadoras aparecem na educação geográfica: novas tecnologias emergem e novas interpretações são decorrentes desse ambiente criado, a metodologia do professor em sala de aula se modifica, alguns recursos ajudam no desenvolvimento do seu trabalho e isso tudo se reflete na avaliação, ou seja, o cenário avaliativo que se adapta às novas tecnologias e repercutem na aprendizagem. Atualmente, o educando tem acesso a meios digitais que, se utilizados de maneira correta no ambiente escolar, poderão favorecer a aprendizagem.

Surgem as imagens, a fotografia, os jornais, os livros, a televisão, o vídeo, computadores, enfim, tudo isso reflete o cenário da educação geográfica. Em virtude das novas tecnologias, o ensino de Geografia deve se integrar ao que é novo e ao que a sociedade de fato precisa aprender.

As estratégias metodológicas devem ser realizadas de acordo com o conteúdo que mais se relaciona com a realidade da sociedade; é necessário trabalhar a essência no que se refere ao espaço geográfico como local de moradia do homem. É importante mencionar que a Geografia escolar deve favorecer o raciocínio geográfico, mas, para isso, deve haver um ensino voltado à construção do conhecimento, e não à memorização dos conteúdos.

O docente, ao ministrar a disciplina de Geografia, deve estar atento à realidade do ambiente vivido na escola e trabalhar os assuntos para que haja favorecimento à aprendizagem do educando, ou seja, deve-se estimular seu senso crítico. $\mathrm{O}$ ambiente escolar precisa contribuir com o estudo do cotidiano do educando, não só a Geografia, mas também as outras disciplinas podem propiciar um ensino voltado à realidade, mostrando a necessidade de se compreender a importância do espaço na estruturação da vida cotidiana. Nessa discussão,

devemos estar insistentemente cientes de como é possível fazer com que o espaço esconda de nós consequências, de como as relações de poder e disciplina se inscrevem na espacialidade aparentemente inocente da vida social, e de como as Geografias humanas se tornam repletas de políticas e de ideologia. (SOJA, 1993, p. 13)

As informações que surgem na atualidade favorecem a construção da consciência espacial para formar cidadãos críticos e, para formar alunos cidadãos, o ensino tem de trabalhar com o cotidiano e a aprendizagem espacial para oportunizar o raciocínio geográfico.

É importante ressaltar que o ensino de Geografia deve estar voltado para a construção do conhecimento, 
e não para a memorização de determinados conteúdos. Muitos associam a Geografia a decorar as capitais de países, mas a Geografia não se resume a isso, e sim representa o espaço geográfico como reflexo da sociedade em suas múltiplas relações, por meio da análise das diversas realidades e problemas existentes em nosso planeta.

O ensino é a assimilação e a construção do conhecimento e, para isso, é necessário que haja sempre o diálogo entre o educador e o educando para que a aprendizagem seja favorável ao despertar social na compreensão dos conteúdos em Geografia.

Nesse sentido, é importante que

esse despertar social do aluno nos faz defender uma forma de ensinar Geografia que possa vir a perscrutar as relações entre sociedade e cultura e as contradições internas que se materializam em diferentes espaços geográficos. Nisso o papel do professor é sobremodo importante, principalmente porque pode oportunizar aos alunos uma compreensão mais sistemática do conhecimento geográfico. (EVANGELISTA, 2007, p. 17)

O grande desafio a ser vivenciado no ensino de Geografia é o desenvolvimento da prática docente por meio de uma educação que não se prenda à transmissão de informações, à memorização ou a aplicar conteúdos de maneira mecânica em situações do cotidiano, mas compreendê-los para que, na aplicação dos conteúdos de Geografia, haja sentido e coerência com a realidade de vivência, ou seja, articular as referências teóricas com a prática.

O professor deve trabalhar com a consciência de que vive num cenário de globalização e considerar as questões pertinentes a uma economia cada vez mais integrada ao espaço geográfico, relacionando este à realidade de vivência dos educandos, ou seja, relacionar os fenômenos de natureza global com os fenômenos de natureza local.

Ensinar Geografia enquanto objeto de ressignificação de seu objeto de estudo é um elemento primordial para que ocorra aprendizagem com qualidade e, em razão disso, é essencial refletir sobre a escola como espaço de socialização dos conhecimentos, ensino e conteúdo curricular que o docente deve trabalhar e, a partir disso, relacionar à vida cotidiana do educando.

No nosso caso, os(as) professores(as) acrescentam atributos ao "ensinar Geografia” em decorrência da ressignificação que fazem do referente Geografia Crítica. Os pressupostos epistemológicos dessa corrente teórica são ressignificados em orientações de caráter essencialmente ideológicos ou vulgarizados em manifestações típicas do senso comum. (SILVA, 2009, p. 9)

O ensino de Geografia deve ser direcionado aos seus pressupostos epistemológicos, mas estes devem ter significado. É importante mencionar outro aspecto fundamental a ser considerado no cenário do ensino de Geografia: que o professor saiba reconhecer o contexto da escola, o lugar em que ela está situada, a população e suas formas de organização, também ter clareza do papel da instituição escolar e das concepções de ideias para que o professor possa construir os instrumentos que permitam o acesso ao conhecimento. É importante relacionar a aprendizagem em geografia com o contexto local, tendo como objetivo mostrar que a Geografia está na sociedade para mostrar sua realidade.

O professor, apesar das dificuldades encontradas no ambiente escolar, precisa ter em mente a importância de ensinar Geografia, ou seja, mostrar o significado da ciência do espaço para com a vida cotidiana, levando-se em consideração seu contexto sociocultural, sua importância na constituição da cidadania e seu significado para a realidade de vivência. Ou seja, um ensino de Geografia que mostre a importância e significação de ensino voltado para a cidadania.

Nesse sentido a importância de se ensinar Geografia apresenta por aspecto principal a possibilidade de que a disciplina traz em seu conteúdo através da discussão de questões vinculadas aos problemas mundiais com reflexos diretos da vida humana. Pra ir além de um simples ensinar, a Educação Geográfica considera importante conhecer o mundo e obter e organizar os conhecimentos para entender a lógica do que acontece. (CALLAI, 2013, p. 44)

Na educação geográfica, é importante que o docente conheça a disciplina detalhadamente e a sua história enquanto disciplina e ciência, e que tenha aproximação com os conteúdos da ciência geográfica com aprofundamento dos estudos e das principais obras que discutem a Geografia. A prática docente no ensino de Geografia pode se dar com recursos convencionais encontrados e disponíveis nas escolas, como, por exemplo, o livro didático, mas, de outro lado, podem ser utilizadas inúmeras fontes que não são necessariamente científicas, mas que advêm de variadas origens do cotidiano de vivência do 
trabalho docente, como notícias de jornais. Estes elementos ajudam o professor na aula de Geografia como recursos alternativos e inovadoras abordagens no ensino de Geografia. De certa forma, ao ensinar Geografia, existem linguagens peculiares a cada realidade, e isto ao longo do tempo se modifica constantemente.

Refletindo sobre as linguagens e a Geografia, no quadro de renovação de seus aportes teórico-metodológicos, torna-se fundamental considerar a especificidade do momento histórico, marcado pela revolução tecnológica concentrada nas tecnologias da informação e nas inovações das técnicas de ensino. (CASTELLS, 1999, p. 21)

A ciência geográfica reflete importante momento de renovação, e a gama de situações que o mundo vivencia é objeto de intensas discussões e reflexões no cenário geográfico. $\mathrm{O}$ momento atual é de renovação do ensino de Geografia; o século XXI se beneficia dos recursos tecnológicos, e diferentes estratégias metodológicas aparecem e se renovam para dar sentido ao cenário educacional. Acima de tudo, o ensino de Geografia deve abarcar diferentes realidades, mas preservando, de fato, sua essência, que é a aprendizagem espacial. Para a leitura e interpretação do espaço, nesse sentido,

nos dias atuais observam-se diferentes linguagens, a partir das quais o ensino de Geografia se nutre para ensinar a ler e interpretar o espaço, linguagens que, ao longo do tempo, foram ressignificadas, aprimoradas e inventadas passando por um processo de metamorfose. (ALBUQUERQUE, 2013, p. 262)

Ensino com diferentes linguagens, que traz sentido inovador à essência do que é ensinar Geografia, ou seja, vivemos um momento de revisão dos conceitos. A disciplina de Geografia na atualidade se insere na importância do contexto social e já existe certa consciência por parte da maioria das pessoas de que esta não é uma disciplina de memorização.

Mediante o exposto, acredita-se que o momento atual é extremamente favorável a uma revisão sobre a disciplina Geografia. Os rótulos da disciplina simplória, enfadonha, mnemônica e descritiva podem precisar ser suplantados para que o conhecimento geográfico assuma a posição de importância no contexto social. Conhecer o espaço confere o poder de nele intervir, por ele reivindicar, com ele se identificar. (ALBUQUERQUE, 2013, p. 262)
Em virtude da revolução tecnológica, existe um universo de possibilidades no ensino de Geografia, e a necessidade de revisão teórico-metodológica torna-se essencial para a aprendizagem significativa. Mas apenas o domínio dos conteúdos, dos procedimentos e das ferramentas metodológicos não basta, é necessário que o docente, no ensino de Geografia, mostre para o educando o que é realmente o significado da Geografia na vida das pessoas.

Ensinar Geografia envolve situações vivenciadas que representam a aprendizagem do aluno enquanto cidadão crítico, fornecendo subsídios para que este possa atuar de maneira ativa, discutindo os problemas vivenciados pela sociedade. $\mathrm{O}$ aluno deve ser constantemente observado pelo professor no processo ensino-aprendizagem.

\section{O PROCESSO ENSINO-APRENDIZAGEM}

A aprendizagem representa a construção contínua de etapas e atividades realizadas pelo docente e pelo educando nas instituições de ensino que objetivam a assimilação dos conhecimentos. O professor exerce o papel de mediador no processo, e o educando precisa estar envolvido no ambiente escolar enquanto ser ativo incluído em situações que possam favorecer a assimilação e a construção do conhecimento. Diante das condições existentes de oferecimento do ensino, pode haver uma educação com ou sem qualidade, a situação em que o aluno está inserido neste processo é a chave para que a aprendizagem possa ocorrer de maneira satisfatória.

O ensino, de fato, consiste na procura constante de alternativas que possam contribuir para a aprendizagem. Envolve a habilidade do professor em saber lidar com as diferentes situações impostas pelo cenário educacional. De acordo com a realidade encontrada nas instituições de ensino, o professor precisa estar atento aos problemas e ter a atitude para mudar o cenário existente procurando uma melhoria da aprendizagem discente.

Libâneo (2004, p. 93) afirma que "ensinar e aprender são duas facetas do mesmo processo, que se realiza através das matérias de ensino sob a direção do professor". As condições internas e externas a escola podem favorecer ou atrapalhar o ensino e a aprendizagem, e a sala de aula apesenta diferentes realidades de acordo com sua localização no que se refere à situação econômica dos educandos. 
O ensino tem por base os conteúdos das disciplinas; a maneira de ensinar por parte do professor e a ação de aprender por parte dos educandos representa o elemento-chave no processo ensino-aprendizagem. No cenário educacional, é possível observar o nível e as habilidades em que o educando se encontra com relação à aprendizagem e, também, que condições apresentam para a assimilação dos conhecimentos.

A qualidade do ensino nas escolas está atrelada não somente a fatores internos e externos, mas também à maneira como o professor trabalha os conteúdos em sala de aula, de que forma está propiciando a assimilação dos conhecimentos e orientando as atividades dos conteúdos realizados nas aulas.

Alguns fatores interferem no processo de ensino, como a situação em que se encontra o domínio de conteúdos por parte de quem ensina e de quem aprende, e a relação desse domínio com situações referentes à vida prática. A capacidade com que o docente faz a divisão do conteúdo em determinadas partes ou unidades, o conhecimento das características e realidades vivenciadas pelos alunos em se tratando de aspectos culturais e econômicos, a facilidade apresentada pelo docente em dominar os métodos de ensino e sua atualização acerca de informações sobre a disciplina contribuem para a aprendizagem.

O ensino faz parte da adequação das situações encontradas no ambiente escolar, representa uma maneira de direcionar os educandos com objetivo de chegar a certos resultados, de acordo com as características do educando com o qual se trabalha.

Em cada caso utilizamos uma forma de ensinar que seja adequada às necessidades do aluno. Segundo as características de cada um, estabelecemos um tipo de atividade que constitui um desafio alcançável, mas um verdadeiro desafio e depois, lhes oferecemos a ajuda necessária para superá-lo. No final fazemos uma Avaliação que contribui para que cada um deles mantenha o interesse em seguir trabalhando. (ZABALLA, 1998, p. 29)

Ensinar é um ato que faz parte da vida humana, é uma necessidade que faz que todos os seres vivos possam sobreviver em um mundo em que depara com variados tipos de problemas. É um desafio, mas também uma situação que todos têm de enfrentar, é possível que seja de alcance a todos, mas isso depende do contexto vivenciado pela sociedade.
Em qualquer tipo de situação em que o ser humano se encontra, o ensinar está presente, ou seja, tudo o que se vive faz parte de um aprendizado. Sempre haverá novas situações e novas aprendizagens, isto é, a aprendizagem é uma tarefa que se leva para o resto da vida. A aprendizagem representa um enriquecimento de informações, que envolve a aquisição de conhecimentos, a análise de conteúdos e uma reflexão acerca das informações que o ser humano adquire em toda sua vivência. Assim,

inicialmente convém salientar que a aprendizagem não é apenas um processo de aquisição de conhecimentos, conteúdos ou informações. As informações são importantes, mas precisam passar por um processamento muito complexo, a fim de se tornarem significativas para a vida das pessoas. Todas as informações, todos os dados da experiência devem ser trabalhados, de maneira consciente e crítica, por quem os recebe. (PILETTI, 2006, p. 31)

Uma situação em que a aprendizagem se desenvolve pode aparecer na vida humana de maneira casual ou também pode ocorrer de maneira organizada, emergindo de acordo com um planejamento específico, para que, deste modo, a aprendizagem possa ocorrer. Nesse sentido, a aprendizagem pode ser definida como um processo de assimilação dos conhecimentos adquiridos durante o ensino, que envolve a coleta de informações, sua análise e seu processamento.

Alguns elementos estão presentes na aprendizagem, por exemplo: hábitos, atitudes e valores, sendo que estes envolvem o ensino. Ou seja, ensino reflete em aprendizagem, envolvendo o conhecimento do fenômeno. Pode-se dizer de fato que o ensino é uma forma de motivação, direcionamento e orientação.

Existem algumas funções que estão ligadas diretamente ao ensino, estas se referem à maneira como o professor apresenta a organização dos conteúdos para a transmissão aos alunos em sala de aula. O professor trabalha os conteúdos de acordo com situações reais, possibilidades, objetivos, metodologias e as expectativas quanto ao processo ensino-aprendizagem, tendo em vista que este ocorra de maneira satisfatória. $\mathrm{O}$ docente, de fato, é responsável pela condução nesse processo, facilitando a aprendizagem.

Ensinar representa um trabalho social, uma tarefa que contribui para a sociedade no que diz respeito à educação das pessoas não só em nível de conteúdos, 
mas também em formação de atitudes e valores. Estas atitudes o ser humano carrega para a vida inteira e para a formação do exercício da cidadania para que este atue de maneira crítica diante de problemas em escala mundial. Na realidade, é uma maneira de contribuir para que as pessoas possam exercer a cidadania.

O ser humano começa a formar opinião na escola, a partir do momento em que atua mediante problemas enfrentados em escala mundial de maneira ativa, apresentando posturas e críticas perante os conteúdos apresentados pelos docentes, na compreensão, na análise e na crítica do que está sendo ensinado.

O professor, no cenário educacional, tem o desafio de proporcionar situações para que ocorra a aprendizagem. Para isso, existe a necessidade de uma conduta ativa no processo de ensino. Ensinar não é apenas repassar as informações aos educandos, e sim contribuir para que este construa seu conhecimento e que possa adquirir saberes que lhes serão úteis para o resto da vida. Portanto,

não se trata, então, nem de simplesmente o professor transmitir conhecimentos para os alunos, nem de apenas mobilizá-los a entender as suas necessidades imediatas. Ou seja, nesse processo nem é passivo o aluno, nem o professor. O aluno é ativo porque ele é o sujeito e, por isso, sua atividade mental ou física é fundamental para a relação ativa com os objetos de conhecimento. (CAVALCANTI, 2002, p. 106)

Ensinar representa trabalhar com o sujeito e saber posicioná-lo diante do processo de ensino, deixando clara sua condição como ser ativo. $\mathrm{O}$ sujeito que apresenta conduta ativa tem a possibilidade de explorar mais profundamente o papel das interações com os outros, parceiros e tutores, na construção de ambientes de aprendizagem. Indivíduos não aprendem apenas explorando o ambiente, mas também dialogando, recebendo instruções, vendo o que os outros fazem e ouvindo o que dizem.

Ensino e aprendizagem constitui uma tarefa, uma atividade que deve ser realizada no dia a dia, uma forma de organização das informações, de processamento, de análise com vistas à assimilação. Para o professor, ensinar é oferecer a oportunidade de aquisição de atitudes, valores e conhecimentos, de que os aprendizandos se tornem cidadãos em uma sociedade com inúmeras cobranças. É uma forma de garantir que o sujeito se adeque às novas realidades impostas pela vida em sociedade. Com isso, o processo de ensino-aprendizagem é, pois, uma tarefa que o estudante deve realizar, e o nosso grande desafio como professores é oferecer-lhe as condições para tanto. Um dilema muito presente na Geografia é o que fazer com tanta informação em relação a cada conteúdo. Cada vez se torna mais claro que a escola não é o lugar da informação, mas da busca e da organização da informação no sentido da construção do conhecimento. A grande questão é auxiliar o aluno a organizar as informações no sentido de entendimento sobre como tais processos naturais e fenômenos atingem a vida das pessoas. (CASTROGIOVANNI, 2000, p. 101)

Deve haver condições necessárias que favoreçam a aprendizagem, e o professor tem o papel de mediador esse processo, tendo o desafio de saber selecionar os conteúdos e oportunizar aos educandos situações que possibilitem o conhecimento. Tudo depende, é claro, de organização e planejamento, de um ambiente organizado com uma equipe que planeja de maneira eficaz, para que haja a construção do conhecimento.

Durante todo o processo, deve haver a assimilação por parte dos alunos e, para Coll (1998, p. 124), "os conteúdos designam o conjunto de conhecimento ou formas culturais cuja assimilação e apropriação pelos alunos é considerada essencial para o seu desenvolvimento e socialização". O autor também afirma que a humanidade tem continuadamente produzido um conhecimento que é patrimônio, tendo em vista nossa disposição para compreender o mundo. A herança deixada por uma sociedade é o conhecimento, e a aprendizagem representa sua assimilação, a vida em um grupo depende do conhecimento adquirido que expressa as formas culturais como a sociedade se comporta.

O conhecimento, ao ser apropriado pelo sujeito, representa poderoso instrumento para construir a cidadania, ou seja, proporciona a formação do aluno cidadão e contribui para que haja o exercício da cidadania. A aprendizagem do educando resulta de todo o processo de ensino que perpassa por adaptação às realidades impostas no ambiente escolar, e o professor deve proporcionar aos educandos situações em que ocorra a aprendizagem de acordo com a realidade do aluno e dos conteúdos em sala de aula. Ou seja,

no processo ensino-aprendizagem, o aluno ao formular seus conceitos, vai operando com os conceitos do cotidiano e os conceitos científicos. Em geral todos têm conceitos 
formulados a respeito das coisas, e a tarefa da escola é favorecer a reformulação dos conceitos originários do senso comum em conceitos científicos. Para tanto é fundamental a capacidade de argumentação, que depende do acesso às informações. (CALLAI, 2013, p. 176)

De fato, a aprendizagem representa o desenvolvimento da cognição que envolve a ação do sujeito inserido no processo de ensino. $\mathrm{O}$ educando tem total capacidade de aprender, mas, para isso, depende do contexto vivenciado, da interação com os outros sujeitos, da eficiência em um ensino de qualidade, do apoio da família, dos sistemas de ensino e do empenho de todos que trabalham com educação. Ou seja,

a aprendizagem, no campo da educação, refere-se a uma teoria em que resulta de uma construção mental realizada pelos sujeitos com base na sua ação sobre o mundo e na interação com os outros. O ser humano tem uma potencialidade para aprender a pensar que pode ser desenvolvida, porque a faculdade de pensar não é inata e nem provida de fora. (LIBÂNEO, 2004, p. 27)

Assim, a concepção de aprendizagem se apoia na ideia de que aprender é fruto de uma construção pessoal, na qual os outros sujeitos são agentes significativos e que interagem para essa construção. No cenário educacional, essa construção ocorre de maneira contínua e deve haver a oferta de condições favoráveis para que ela ocorra.

O sujeito, ao longo do tempo de vivência, vai construindo e reconstruindo o seu modo de pensar; na realidade, se refere a uma evolução da mente e a interação com os outros beneficia o desenvolvimento intelectual. De fato, nada nasce pronto e tudo é passível de ser modificado, e a aprendizagem é a adaptação das situações impostas pela sociedade e uma maneira de saber lidar com elas.

$\mathrm{O}$ ser humano interage com o meio em que vive e, por meio disso, surgem ideias e informações sempre atualizadas acerca de seu espaço de vivência. O meio físico e social representam palcos de novas informações. É importante ressaltar que a aprendizagem representa uma contínua construção, de fato não existe nada pronto, sempre há algo para ser aperfeiçoado, melhorado ou transformado. A interação entre os indivíduos em seu meio fisico e social representa a peça-chave para favorecer a construção de novos conhecimentos.

\section{Prática docente}

O ato de educar não é algo que significa apenas ministrar uma aula, mas um compromisso docente com a ação didática e com a disciplina que será ministrada no ambiente escolar. A prática docente dos dias atuais necessita de condições adequadas, e é importante que haja motivação em executar o trabalho na educação básica. Existe a necessidade de um questionamento a respeito dos problemas da atualidade, seja nos locais de moradia dos educandos e de outros lugares, além de um olhar crítico dos fenômenos que ocorrem hoje.

A formação em licenciatura qualifica o profissional da educação para atuar no ensino básico e, também, para prosseguir os estudos em nível de pós-graduação, podendo, inclusive, de acordo com a titulação, atuar no ensino superior.

Para acompanhar a mudança no processo educacional, o professor teve de se aperfeiçoar em sua maneira de trabalho em sala de aula. Diferentes práticas pedagógicas caracterizam o processo de adaptação do professor mediante novas realidades impostas pelo processo de globalização e por novas concepções pedagógicas, tendo o educando como o centro do processo ensino-aprendizagem. Nesse contexto,

o professor, como líder, é o grande responsável pelo bom relacionamento. Sua influência na sala de aula é muito grande, e a criação de um clima psicológico que favoreça ou desfavoreça a aprendizagem depende principalmente dele. Entretanto, a preocupação com o bom relacionamento na sala de aula não pode fazer com que deixemos de nos preocupar com o que ensinar. (PILLETI, 2006, p. 252)

As transformações da sociedade necessitam de uma prática docente que esteja adequada às novas situações que caracterizam a organização da vida em sociedade. Envolve o exercício da cidadania, principalmente no plano dos saberes e competências necessárias para a renovação das funções no mercado de trabalho. Por meio do ensino e da prática avaliativa, o docente pode fazer um trabalho com seus alunos sobre a importância dos conteúdos e suas aplicações na vida cotidiana.

A atuação docente no Brasil passou por adaptações com o decorrer dos $\operatorname{anos}^{1}$, a prática docente passou por

1 Quando se fala em regulações, destacam-se os ajustes a que a profissão docente teve de se adaptar em virtude das transformações sofridas pelo cenário educacional. 
metamorfose em virtude dos inúmeros acontecimentos ocorridos no cenário nacional e mundial, em virtude do surgimento das tecnologias aplicadas à educação e dos recursos didáticos, que ajudaram a melhorar o processo ensino-aprendizagem.

O professor hoje, diante das situações reais, tem o desafio de conviver com as adversidades para desenvolver seu trabalho e realizar a prática pedagógica que possibilite a construção do conhecimento, e que saiba lidar com os problemas enfrentados nas instituições de ensino, sabendo de que o reflexo de sua prática influenciará diretamente no comportamento e na vida do educando.

Um professor que ministra uma aula utilizando as técnicas de ensino mais adequadas, sendo pontual com os horários e utilizando um bom material didático, pode ser eficiente sem ser eficaz. Ele será apenas eficiente se, apesar de tudo o que faz, não obtiver resultados. Mas será eficiente e eficaz quando os alunos aprenderem o que ele ensinou. A eficácia, portanto, é a ação que alcança resultados. Eficiência é apenas a ação realizada de acordo com as normas estabelecidas, mas sem resultados. (PILETTI, 2006, p. 45)

De certo maneira, pode-se afirmar que ser professor no Brasil é uma tarefa que requer vocação e vontade de exercer um trabalho social que contribua para a formação da cidadania do educando e o leve a perceber a realidade. Mas a grande questão a se discutir se relaciona a que tipo de profissional está sendo formado para exercer a atividade docente nas escolas. $\mathrm{E}$ a resposta para isso está no contexto político, social e cultural em que viveu nosso país nas últimas décadas. Inovadoras práticas pedagógicas refletem no profissional que está sendo formado e em que qualidade e concepção pedagógica o docente se encontra para exercer suas atividades.

A complexidade de se trabalhar como professor exige que este tenha de lidar com uma gama de situações desfavoráveis e, como reflexo, o cenário educacional depara cada vez mais com profissionais desmotivados e sem vontade de exercer sua profissão. Existe a necessidade de uma política educacional que não só valorize o professor, mas que trabalhe sua motivação para que ele exerça sua profissão contribuindo para a melhoria no processo educacional. Em se tratando de cenário educacional, é necessário que haja a reformulação da concepção acerca do processo de formação de professores que envolvem, além da academia, as políticas do Estado para com a educação. Quando se fala em repensar o processo de formação, discutem-se concepções pedagógicas que possam estimular a aprendizagem dos educandos e práticas pedagógicas que propiciem a construção do conhecimento.

Ou seja, é necessário refletir acerca do significado da experiência e do saber universitário como prática profissional que reflete na atuação do professor em sala de aula. Resumindo, existe a necessidade de investigar como está a vida dos professores para se ter a noção de qual é sua real situação em sala de aula, e pensar o tipo de ensino e de avaliação que está sendo trabalhado. O docente deve acreditar em sua capacidade de desenvolver um trabalho que, apesar das dificuldades, possa ocorrer de maneira eficiente e que seja apenas uma questão de o profissional da educação acreditar em sua força de trabalho e na capacidade cognitiva dos discentes.

A prática docente apresenta por reflexo a relação professor-aluno e se caracteriza pelo que se quer ensinar e por aquilo que o educando está assimilando, expresso pela necessidade de selecionar o conteúdo e utilizar a metodologia de acordo com os referenciais adotados.

\section{CONSIDERAÇÕES FINAIS}

De acordo com a análise das discussões, verifica-se que a gestão e o planejamento escolar precisam estar mais relacionados à realidade docente. O caminho benéfico para a educação geográfica está vinculado ao processo de ensino, ao acompanhamento sistemático do educando, aos objetivos do planejamento e, além disso, que o ensino ocorra de maneira que possa favorecer a construção do conhecimento. É importante que, mesmo com as adversidades, o educador considere o meio sociocultural e as habilidades dos educandos, tornando o ensino significativo e enriquecedor para o conhecimento.

Algo que pode ser incorporado pelos professores de Geografia está relacionado a um diagnóstico do perfil do educando. É importante que este diagnóstico ocorra no início do ano letivo ou quando houver necessidade de planejar a prática educativa em Geografia. No decorrer do ano letivo, é importante que haja a identificação das facilidades ou dificuldades dos educandos em relação às habilidades e aos conteúdos trabalhados.

A prática docente precisa de avanços para o ensino de qualidade e, infelizmente, em muitos casos, as instituições de ensino deixam muito a desejar. A razão dessa situação está na falta de motivação dos professores 
e educandos. Em virtude disso, os jovens da atualidade devem entender o valor da educação para a vida cotidiana, ou seja, para as situações futuras que irá enfrentar.

É importante mencionar que o professor de Geografia representa o papel de mediador no processo de ensino, e o educando apresenta uma relação de aquisição e construção de conhecimentos. Diante das condições existentes de oferecimento de ensino e das possibilidades, a educação pode, sim, ocorrer com qualidade, mas para isso é fundamental que o professor perceba a situação do educando dentro deste processo.

É importante mencionar que três elementos interagem com a educação geográfica: os conteúdos, o ensino e a aprendizagem, formando o conjunto básico que vai ocorrer com o nível de assimilação dos educandos a partir da construção dos conhecimentos e que representa a estrutura básica que caracteriza todo o processo na ação pedagógica do professor de Geografia.

Ensinar Geografia representa um trabalho de contribuição para a sociedade no que diz respeito à educação e à formação de atitudes e valores dos educandos enquanto cidadãos, e estas atitudes o ser humano carrega para a vida inteira, podendo contribuir para a resolução dos futuros problemas que serão enfrentados na sociedade.

\section{REFERÊNCIAS}

ALBUQUERQUE, M. A. M.; FERREIRA, J. A. S. (org.). Formação, pesquisa e práticas docentes: reformas curriculares em questão. João Pessoa: Mídia, 2013.

\section{CALLAI, H. C. A formação do profissional da}

Geografia: o professor. Ijuí: Editora Unijuí, 2013.

CASTELLS, M. A questão urbana. 4. ed. São Paulo: Paz e Terra, 1999.

\section{CAStrogiOVAnNi, A. G. Ensino de Geografia:} práticas e textualizações no cotidiano. Porto Alegre: Editora Mediação, 2000.
CAVALCANTI, L. S. Geografia, escola e construção de conhecimentos. Campinas: Papirus, 1991.

\section{CAVALCANTI, L. S. Geografia e práticas de en- sino. Goiânia: Alternativa, 2002.}

COLL, G. et al. O construtivismo na sala de aula. São Paulo: Ática, 1998.

EVANGelista, A. M. A região no ensino de geografia: fundamentos da prática professoral. 2007. Tese (Doutorado em Educação) - Universidade Federal de Fortaleza, Fortaleza, 2007.

LIBÂNEO, J. C. Didática. São Paulo: Cortez, 2004.

LÜCK, H. Gestão escolar e formação. Em Aberto, Brasília, DF, v. 17, n. 72, p. 11-34, 2000.

PIAGET, J. A equilibração das estruturas cognitivas: problema central do desenvolvimento. Rio de Janeiro: Zahar, 1976.

SILVA, J. S. O ser professor de geografia no mundo contemporâneo. In: ENCONTRO DE PESQUISA EM EDUCAÇÃO DA UFPI, 5., 2009, Teresina. Anais [...]. Teresina: UFPI, 2009. p. 1-14.

SOJA, E. Geografias pós-modernas: a reafirmação do espaço na teoria social crítica. Rio de Janeiro: Zahar, 1993.

TARDIFF, M. O ofício do professor: história, perspectivas e desafios internacionais. Petrópolis: Editora Vozes, 2008.

TURRA, C. et al. Planejamento de ensino e avaliação. 11. ed. Porto Alegre: Editora Sagra, 2002.

VESENTINI, J. W. Geografia e ensino: textos críticos. Campinas: Papirus, 1987. 